\title{
Agricultural Growth, Poverty and Inequality in Developing Countries
}

DOI:

10.1057/s41301-016-0009-1

\section{Document Version}

Accepted author manuscript

Link to publication record in Manchester Research Explorer

\section{Citation for published version (APA):}

Imai, K., Cheng, W., \& Gaiha, R. (2015). Agricultural Growth, Poverty and Inequality in Developing Countries. Development, 58(2-3), 230-236. https://doi.org/10.1057/s41301-016-0009-1

\section{Published in:}

Development

\section{Citing this paper}

Please note that where the full-text provided on Manchester Research Explorer is the Author Accepted Manuscript or Proof version this may differ from the final Published version. If citing, it is advised that you check and use the publisher's definitive version.

\section{General rights}

Copyright and moral rights for the publications made accessible in the Research Explorer are retained by the authors and/or other copyright owners and it is a condition of accessing publications that users recognise and abide by the legal requirements associated with these rights.

\section{Takedown policy}

If you believe that this document breaches copyright please refer to the University of Manchester's Takedown Procedures [http://man.ac.uk/04Y6Bo] or contact uml.scholarlycommunications@manchester.ac.uk providing relevant details, so we can investigate your claim.

\section{OPEN ACCESS}




\section{Agricultural Growth, Poverty and Inequality in Developing Countries}

Katsushi S. Imai, Wenya Cheng, and Raghav Gaiha

Email: Katsushi.Imai@manchester.ac.uk, Wenya.Cheng@macnhester.ac.uk;

raghavdasgaiha@gmail.com

Running Header: Agricultural Growth, Poverty and Inequality

Abstract: Drawing upon cross-country panel data for developing countries, the present study shows that agricultural growth is the most important factor in reducing inequality and poverty, and growth acceleration. This is in striking contrast to the dominant view that urbanization is key to growth and elimination of extreme poverty. There is thus a case for a drastic shift away from rural-urban migration and urbanization as main drivers of growth and elimination of extreme poverty, and towards revival of agriculture in the policy discourse that should drive the advancement of the 2030 Sustainable Development Agenda.

Keywords: inequality; poverty; growth; agriculture; non-agriculture; urbanization

\section{Introduction}

The main purpose of this article is to critically assess the role of agricultural sector growth in overall growth, poverty reduction and inequality changes during the ruralurban transformation in developing countries. It draws upon our two recent studies, Imai and Gaiha (2014) and Imai et al. (2014).

It is claimed by the World Bank (2013a) that Millennium Development Goal (MDG) 1A of halving extreme poverty by 2015 was achieved in $2010-5$ years ahead of the deadline. Yet 970 million remained poor in 2015, with 84 percent concentrated in South Asia and sub-Saharan Africa. The latter is also the only region that failed to achieve MDG 1A by 2015. Global poverty remains a rural problem with more than three-fourths of the extremely poor located in rural areas. However, as global poverty fell, so did the gap between rural-urban poverty. It reduced by half in East Asia and the Pacific by 2008, while in sub-Saharan Africa, Latin America and the Caribbean, and South Asia, there was less progress. 
The World Bank (2013a) makes an important contribution to the discourse on MDGs by disaggregating progress into rural and urban components. In doing so, it offers striking examples of the continuing rural-urban disparities in several MDGs. It does not, however, disaggregate the 970 million estimated to have remained in extreme poverty in 2015 into those based in rural and urban areas. This would be crucial for designing appropriate policy interventions.

Furthermore, the World Bank (2013a) makes a powerful case for rapid and efficient urbanization as key to overall poverty reduction. It rests on better utilization of agglomeration economies and efficient rural-urban migration. Indeed, it is argued that these could also result in speedier rural poverty reduction. An important link in the chain is small cities (somewhat controversially referred to as 'the missing middle'): As their weak infrastructure, and poor hygiene and sanitation are likely to turn them into slums with growing rural-urban migration, investment must be directed to such cities to better exploit their growth potential.

Curiously, rural-urban migration, contributing 40 percent of the increase in urban population over the period 2010-2030, has two sides to it. One is the poverty reduction through the growth of small cities and rapid urbanization. The premise is that more ruralurban migration will have a substantial payoff in terms of higher wages in rural areas and greater diversification of rural economies. If this argument is turned on its head, it could be argued that more efficient land, labour and credit markets and better infrastructure in rural areas would not only help raise agricultural productivity but also enable diversification of rural economies. In particular, the dynamic between farm and non-farm activities has assumed greater significance with the diversification of the former (Thapa 
and Gaiha, 2014). Non-farm activities are not just remunerative but also help stabilize rural incomes. Consequently, the rapid pace of rural-urban migration - highest in Latin America and the Caribbean and lowest in South Asia and sub-Saharan Africa - will slowdown. Better and more diversified livelihood opportunities in rural areas cannot be discarded as the inferior option relative to the more rapid and efficient urbanization thesis with considerable risks of uncontrollable growth of slums with pervasive multiple deprivations (e.g. malnutrition and infectious diseases). In any case, available evidence is not robust enough to clinch the argument developed in, for instance, The Global Monitoring Report 2013 (World Bank, 2013a) and Collier and Dercon (2014), among several others.(1)

Much of sustained reduction in poverty hinges on how growth and inequality interact - a subject that has gained prominence in a context of rising inequality in a large part of the developing world in the last two decades. As argued in a recent United Nations report (United Nations, 2013), addressing inequality is not just a moral imperative but also a necessity for sustainable development(2). Evidence points to the powerful and corrosive effects of inequality on poverty reduction, social cohesion and stability. A major part of the solution lies in fostering inclusive and sustainable rural transformation through a comprehensive approach to food security and nutrition, addressing the linkages between agriculture, health, education, water, energy, gender equality and poverty.

As discussed in Imai et al. (2014), there has also been a lively debate among both policymakers and academics as to whether structural transformation away from agriculture into manufacturing and services will accelerate growth and/or reduce poverty. This transformation is normally accompanied by an occupational shift from agricultural 
activities towards more remunerative non-agricultural activities with a time lag, and inequality rises as an economy's heavy dependence on agriculture evolves into greater dependence on non-agricultural sectors. The structural transformation involves two related, but distinct processes: (i) development of rural non-agricultural sector in rural areas; and, (ii) urbanization in which workers in rural areas typically migrate and seek employment in non-agricultural sector in urban areas - including both mega cities and secondary cities or towns. These processes may have different implications for aggregate poverty reduction.

A recent study by Christiaensen and Todo (2014) - CT hereafter - argued that the past empirical literature has investigated either the role of urbanization in development and poverty reduction without disaggregating the urban sector into mega cities and secondary cities/towns or suburbs in urban areas, or the role of rural non-agricultural sector in poverty reduction (without distinguishing secondary towns). They argued that it is necessary to examine the role of the 'missing middle' (the aggregate of secondary towns and rural non-agricultural sector) and of 'mega cities' to better understand the relation between urbanization and poverty reduction. CT's study found that migration out of agriculture into 'the missing middle' is key to faster poverty reduction than agglomeration in mega cities.

We argue in Imai et al. (2014) that it will be misleading to treat secondary towns and rural non-agricultural sector as one aggregate sector in analyzing the process of poverty reduction because of different locations of these sectors and dynamics between nonagricultural and agricultural sectors, and between non-agricultural in rural areas and secondary towns. In this article, we have analyzed the rural non-agricultural sector as a 
separate sector by disaggregating 'the missing middle' into rural non-agricultural sector and secondary towns. We find by econometric estimations applied to cross-country panel data for developing countries, that, if the 'missing middle' is disaggregated into secondary towns and rural non-agricultural sector (i.e., if the whole country is broken down into (i) rural agricultural sector, (ii) rural non-agricultural sector, (iii) secondary towns, and (iv) mega cities), the development of (i) rural agriculture sector as well as (ii) rural non-agricultural sector - rather than (iii) secondary small towns - are the most important for acceleration of poverty reduction. It has also been observed that growth in mega cities does not contribute to poverty reduction, or in some cases, increases poverty. So the case for urbanization-especially secondary towns-as the key driver of elimination of extreme poverty rests on a somewhat arbitrary merging of non-agricultural activities in rural areas and secondary towns, and results that exaggerate the importance of urbanisation.

The poverty reducing effect of urbanization is largely through economic linkage effects rather than through the direct movement of the rural poor to urban areas. This is justified on the grounds that rural-urban migrants, on average, are less poor and more educated than rural non-migrants. The economic linkage effects are transmitted through four channels: consumer linkages, urban-rural remittances, the changing rural land/labour ratios, and nonfarm employment.

Our study departs from the extant literature in the following two ways. First, based on Imai and Gaiha (2014), we examine the dynamic linkages between agricultural growth and non-agricultural growth using a dynamic panel model applied to cross-county panel data. We apply this model separately for non-agricultural sector growth and agricultural 
sector growth in which both lagged agricultural growth and lagged non-agricultural growth are used as explanatory variables in each model after taking account of the endogeneity of the past growth. This will enable us to estimate effects from the nonagricultural sector to the agricultural sector, and vice versa. Second, we will extend the CT study and provide new results based on Imai et al. (2014) to identify the role of development of the rural agricultural sector - as opposed to the role of urbanisation - in reducing poverty.

The rest of the article is organized as follows. The next section focuses on the data sources, while the following summarizes and discusses the main results of Imai and Gaiha (2014) and Imai et al. (2014). The final section offers concluding observations.

\section{$\operatorname{Data}(3)$}

All the estimations are based on cross-country panel data that have been compiled from World Development Indicators (WDI) 2013 (World Bank, 2013b). The data on education and a few other variables are based on Barro and Lee (2010). To construct the proxy for institutional qualities, we have used the World Bank's World Governance Indicators(4). Following Herzer and Vollmer's (2012) work, which estimated the relationship between economic growth and inequality, we have used the inequality data based on the Estimated Household Income Inequality (EHII) Data Set - combining the UNIDO and the Deininger and Squire (1998) datasets - taken from the University of Texas Inequality Project(5) and 46 countries for the period 1970-2008 have been selected to avoid the problem of missing observations. The EHII data is based on Theil's T statistic measured across sectors within each country where the classifications of sectors are standardized based on UNIDO's 
Industrial Statistics and Eurostat to facilitate international comparisons. Beside, we have further expanded the EHII data on inequality by supplementing them with the World Bank data (World Bank, 2013b) on inequality (the Gini Index) on the PovcalNet, by estimating the EHII data on inequality by the World Bank data (World Bank 2013b) using Ordinary Least Squares and replacing the missing observations by the predicted values. We have also used the data on price uncertainty of 46 export commodities downloaded from World Integrated Trade Solution (WITS — an interface that provides UNCOMTRADE data) for all available countries, from the period 1960 - 2006. We have also used the data of the share of people in agricultural sector available from FAO-STAT in 2013 and have derived the approximate share of rural non-agricultural population as the difference between the share of rural population in the total population (calculated from World Bank 2013b) and the share of population in the agricultural sector in the total population (taken from FAO-STAT 2013). Definitions of most of the variables closely follow the CT study. For instance, the share of population in mega cities is defined as the population share living in cities with a population of more than one million and is based on the United Nations' World Urbanization Prospects (UNWUP). Real GDP per capita is taken from World Bank (2013b). We have used the World Bank's POVCAL data as well as WDI 2013 to update the international poverty data, that is, poverty headcounts and poverty gaps based on US\$1.25 and US\$2 (PPP).

\section{Results}

This section offers a selective summary of the econometric results in Imai and Gaiha (2014) and Imai et al. (2014). 
Agricultural growth versus non-agricultural growth in poverty and inequality reduction

Imai and Gaiha (2014) have developed a comprehensive critique of Christiaensen et al. (2011) using the cross-country panel data. First, our results based on the (unbalanced) panel data covering 50 countries for 1969-2010, either annual panel or the panel based on three-years averages, show that agricultural growth has a statistically significant effect on non-agricultural growth in a dynamic model (Blundell and Bond, 1998) that takes account of the dynamic inter-linkages between agricultural and non-agricultural sectors. This result is consistent with the important role of agricultural sector growth in promoting overall growth over time. However, this is not the case for low-income countries. That is, as a country grows and shifts from the low-income and the middle-income categories, the nature of agriculture typically changes from subsistence-oriented farming to more commercialized and market-oriented farming and has a closer linkage with nonagricultural sector. In some cases, non-agricultural growth has been found to promote agricultural growth. Our results also imply that human capital enhances agricultural growth, while precipitation enhances agricultural growth in low-income countries.

Second, agricultural growth tends to slow down the expansion of inequality over time. That is, if a country experiences a higher level of agricultural growth, the pace of inequality reduction is accelerated dynamically. We do not see these effects for nonagricultural growth.

Third, the role of agriculture in reducing accentuation of inequality is found to be undermined by ethnic fractionalization, which tends to make economic inequality more 
persistent. The countries in sub-Saharan Africa tend to experience slower changes in improvement in equality as a result of growth in both agricultural and non-agricultural sectors. South Asian countries also tend to have slow changes as a result of agricultural growth.

Fourth, agricultural growth has a stronger and significant effect in reducing both poverty headcount ratio and poverty gap regardless of whether the US\$1.25 a day poverty line or the US 2.00 a day poverty line is adopted, while there is no statistically significant effect of non-agricultural growth. The pattern of the results is unchanged if we restrict the sample only to middle-income countries where agricultural growth is found to reduce poverty regardless of which definition of poverty is used. On the other hand, in the case of low-income countries, with the caveat that this is based on a small number of observations, we find a statistically significant coefficient estimate for agricultural growth only in one case for poverty gap based on US\$1.25 line. Poverty reducing effects of agricultural growth are weaker in terms of their magnitude for low-income countries than for middle-income countries. Non-agricultural growth is negative and statistically insignificant for both middle and low-income countries, with the coefficient estimates larger for the latter. Broadly consistent with Christiaensen et al. (2011), we confirm that agricultural growth has a stronger poverty-reducing effect than non-agricultural growth.

\section{Urbanization versus Rural Development in Poverty Reduction}

In Imai et al. (2014), we have extended Christiaensen and Todo (2014) (or CT) to further assess the role of agricultural sector in the rural area in promoting economic growth and reducing poverty in the following three ways. First, unlike the CT study, we have treated 
the rural non-agricultural sector as a separate sector by disaggregating 'the missing middle' into the rural-non-agricultural sector and secondary towns. To do so, we have used the share of people in agricultural sector available from FAO-STAT in 2013 and have derived the approximate share of rural non-agricultural population as the difference between the share of rural population in the total population (calculated from WDI in 2013) and the share of population in the agricultural sector in the total population (taken from FAO-STAT 2013). Second, we have updated the data coverage to 2010, covering the period 1980-2010. Third, we have used different specifications in the following ways, e.g., by estimating either the level of poverty headcount or changes (both in logarithm) by either the level of sectoral population shares or their changes (both in logarithm).

Our econometric results are summarized as follows. First, development in the rural agricultural sector is the most important for poverty reduction among the four sectors, followed by the rural non-agricultural sector, small and secondary towns and mega cities, which is in sharp contrast with the results in the CT study. For instance, it can be surmised that, if agricultural share change increases by 10 percent, the reduction of poverty headcount ratio based on the US $\$ 1.25$ poverty line tends to increase by 8.6 percent. For the same increase, the reduction of poverty headcount gap based on the US $\$ 1.25$ poverty line tends to increase by 12.5 percent.

Second, the role of rural non-agricultural sector in poverty reduction is observed in some cases, but the pattern of the results is less consistent or weaker than the results for the agricultural sector. Third, it is clearly observed that the growth in mega city sector has no role in poverty reduction. Overall, there is no evidence in favour of poverty-reducing 
roles of mega cities. Finally, it is observed that increase in conflict intensity and improvement in institutional quality are important for poverty reduction.

\section{Concluding observations}

Drawing upon cross-country panel data for developing countries, the present study sheds new empirical light on the dynamic and long-term linkages among agricultural and nonagricultural growth, inequality and poverty in developing countries.

First, we generally observe strong growth linkages between agricultural and nonagricultural sectors. Second, agricultural growth is found to reduce accentuation of inequality, or accelerate inequality reduction. Third, the degree of ethnic fractionalization is key to explaining the magnitude of negative linkages between agricultural/nonagricultural growth and inequality changes. Fourth, agricultural growth reduces poverty both headcount ratios and poverty gaps - in both middle-income and low-income countries. Fifth, by disaggregating 'the missing middle' into rural nonfarm economy and secondary towns, the present study has found that (i) development of rural agricultural sector is the most poverty reducing; (ii) rural non-agricultural sector is poverty reducing in some cases, but its magnitude is much smaller than that of rural agricultural sector; and (iii) higher population in mega cities has no role in poverty reduction. In fact, it is 'poverty-increasing' in a few cases.

Recent research has questioned the key roles of agricultural growth and of smallholders in particular. We are sceptical of these views as we find them ill-informed and potentially misleading. Overemphatic endorsements of promoting rural-urban migration and concomitant shift of resources towards efficient urbanization are robustly rejected by our 
analysis, which rather reinforces the case for the revival of agriculture. The agricultural sector continues to have strong linkages with the non-agricultural sector and has substantial potential for reducing inequality and poverty. More seriously, the lop-sided shift of emphasis to urbanization not only rests on shaky empirical foundations, but could also mislead policymakers and donors. Those left behind in rural areas - especially the poor - deserve better and more resources to augment labour productivity in agriculture to speed up overall growth, curb rising inequality and eliminate worst forms of deprivation in the scenario of the new 2030 Sustainable Development Agenda. It is conjectured that this may even be more cost-effective than the urbanization strategy. Specifically, more emphasis should be placed on policies (e.g. rural infrastructure) that enhance support to rural agricultural sector and rural non-agricultural sector.

\section{Acknowledgements}

This study is funded by IFAD (International Fund for Agricultural Development). We are grateful to Thomas Elhaut, Constanza Di Nucci and Alessandra Garbero at IFAD, for their enthusiastic support and guidance throughout this study and for their insistence on highest standards of analytical rigour. The views expressed are personal and not necessarily of the organizations to which we are affiliated or of IFAD.

Notes

1 See Imai and Gaiha (2014) for a detailed critique of Collier and Dercon (2014).

2 As noted by Doyle and Stiglitz (2014), "There are ....substantial links between violence and "horizontal inequalities" that combine economic stratification with race, ethnicity, religion or region. When the poor are from one race, ethnicity, religion or region, and the rich are from another, a lethal destabilizing dynamic often emerges' (p.4).

3 See Imai and Gaiha (2014) and Imai et al. (2014) for further details of the data.

4 http://info.worldbank.org/governance/wgi/index.asp.

(5) http://utip.gov.utexas.edu/data.html.

\section{References}

Barro, Robert J. and Jong-Wha Lee (2010) 'A New Data Set of Educational Attainment in the World, 1950-2010', NBER Working Paper No. 15902. Cambridge, MA:

NBER. 
Blundell, Richard andStephen Bond (1998) 'Initial conditions and moment restrictions in dynamic panel data models', Journal of Econometrics, 87(1): 115-143.

Christiaensen, Luc, Lionel Demery and Jesper Kühl (2011) 'The (evolving) role of agriculture in poverty reduction: An empirical perspective', Journal of Development Economics, 96(2): 239-254.

Christiaensen, Luc and Yasuyuki Todo (2014) 'Poverty Reduction during the RuralUrban Transformation -The Role of the Missing Middle', World Development, 63: 4358.

Collier, Paul and Stefan Dercon (2014) 'African Agriculture in 50 years: Smallholders in a Rapidly Changing World?', World Development, 63: 92-101.

Deininger, Klaus and Lyn Squire (1998) 'New ways of looking at old issues: inequality and growth', Journal of Development Economics, 57(2): 259-287.

Doyle, Michael W. and Joseph E. Stiglitz Stiglitz (2014) Eliminating Extreme Inequality: A Sustainable Development Goal, 2015-2030, New York: UN Roundtable on 'The Treat of Growing Inequalities', 20 January 2014.

Herzer, Dierk and Sebastian Vollmer (2012) 'Inequality and growth: evidence from panel cointegration', Journal of Economic Inequality, 10(4): 489-503.

Imai, Katsushi S. and Raghav Gaiha (2014) 'Dynamic and Long-term Linkages among Growth, Inequality and Poverty in Developing Countries', DP2014-33, Kobe University, Japan.

Imai, Katsushi S. , Raghav Gaiha and Alessandra Garbero (2014) 'Poverty Reduction during the Rural-Urban Transformation: Rural Development is still more important than Urbanisation?' BWPI Working Paper, WP204/2014. 
Thapa, Ganesh and Raghav Gaiha (2014) 'Smallholder Farming in Asia and the Pacific: Challenges and Opportunities', in Peter B. R. Hazell and Atiqur Rahman (eds.) New Directions in Smallholder Agriculture, Oxford and Rome: Oxford University Press \& International Fund for Agricultural Development.

United Nations (2013) Inequality Matters, Report on the World Social Situation 2013. New York, United Nations, http://www.un.org/en/development/desa/publications/world-social-situation2013.html.

World Bank (2013a) Global Monitoring Report 2013: Monitoring the MDGs, Washington, DC: World Bank.

World Bank (2013b) World Development Indicators, Washington, DC: World Bank. 